\section{No Easy Cure for Migraine}

\section{from a Correspondent}

"I Have my own remedy," said Sir George Godber, in his address to the second Migraine Symposium, held at the National Hospital, Queen Squarc, on November 24. With this remark, Sir George, who is chicf medical officer at the Ministry of Health, associated himself with the many migraine sufferers who have learnt to manage their headaches and the associated symptoms after years of trial and error. For them and for others whose migraine is still unmanageable, the second symposium was a sort of progress report on current research and therapy. Patients who aro treated with mono amine oxidase inhibitors and who include certain foods-particularly chocolate and cheese-in their dict tend to suffer from headache and hypertension; the similarity to the dietary factors in migraine was noted. Certain amines, in particular tyramine and dopamine, have becn implicated as the causal agents when they are contained in the diet, and gain access to the general cireulation. It has now been demonstrated that $100 \mathrm{mg}$ of tyramine taken orally will induce migraine in patients with a convineing dictary history, and who normally exclude foods containing these amines from their diet. On the other hand, there does not appear to be any deficiency of mono amine oxidase in the temporal artery of migrainous subjects when a small biopsy of this artery is removed in an acute attack and stained histochemically. There is increasing interest in the action of amines on blood vessels in vivo and in vitro, and the relevance of these findings to migraine may be significant.

On the therapeutic side, Sir Derrick Dunlop, Extra Physician to the Queen, and chairman of the Ministry of Health's committee on the safety of drugs, reviewed the current methods of trcatment. Ergotamine, either orally, by inhalation, injection or in the form of a suppository, remains the most effective form of treatment in an attack, if it is taken sufficiently carly. Methysergide is a useful prophylactic, but when taken in adequate doses may lead to inflammatory fibrosis. There have been reports of the development of retroperitoneal fibrosis, valvular heart disease and pleuropulmonary fibrosis during methysergide therapy. Prompt reduction in the dose of the drug does lead to regression of the side effects.

The development of newer drugs and the pharmacological investigation of other compounds of ergot was the subject of one of the papers. Of the com. pounds investigated, at least one, 1-methyl-ergotamine, deserves clinical trials. It is difficult to design such trials and equally difficult to assess the effectiveness of a particular drug or regime in a subjective condition such as a headache. An added difficulty, described in one of the contributions, is that patients often do not take the drugs as prescribed. This is demonstrated by the amount of the drug returned by the patients on their next visit to the doctor. Despite the many pitfalls, clinical trials are obviously essential in estab. lishing the value of any new treatment, and conflicting results may be explained by the nature of the trial or the selection of patients admitted to it. The use of hormones in migraine was the subject of another contribution, which described the trial of a progestagen as a prophylactic in migraine. While results are not yet complete, the initial response is not encouraging.

\section{Viruses and Cancer}

A LARGE audience attended a review lceture on virus and eancer, given by Professor J. F. Enders at the Royal Society on December 8. Professor Enders was concerned with the problems of the relationship of the virus to the transformed cell, as illustrated by experiments with the oncogenic agent simian virus 40 . He posed two questions. Does the virus persist in transformed cells and, if so, in what state? Does the virus specifically condition the shift from normal to cancerous state? The fact that certain viruses are capable of inducing solid tumours or leukaemias when introduced into a susceptible host under the appropriate conditions has been known since the beginning of the century. As an introduction to his lecture, Professor Fnders outlined some of the features of oncogenic viruses; they occur in four of the six classes of animal viruses and, in general, do not seem to differ biologically or biochemically from non-oncogenic viruses. They do, however, have two outstanding features. Referring to oneogenic members of the adeno and papova viruses, he pointed out that they replicate in the nucleus and that the expression of the viral genome is partly suppressed so that production of new particles is stopped short of completion. Attempts to isolate these infectious viruses from tumours which they induce have failed, and this has formed the subject of much investigation. In addition, because they replicate in the nuoleus, these viruses can react directly with cellular DNA which, as might be expected, is reflected in unusual changes in the normal functions of both the virus and cell. Professor Enders described how, for simian virus 40 , both direct and indirect evidence has been produced to show that the viral genome can be expressed in at least two different ways in the transformed cell. Interesting indirect evidence which has come from immunological procedures has led to the discovery of two new virusassociated antigens in the transformed cell: the $S$ antigen which only occurs in the cell nucleus, and the $T$ or transplantation antigen. Professor Enders and his associates have shown that $S$ antigen can appear in the absence of $T$ antigen in cells which have been exposed to SV40. Whether or not such cells become oncogenic as a result of exposure to the virus has not yet been established.

Professor Enders related how he and his associates had investigated the phenomenon of tumour progression and had shown that, when hamsters are inoculated intravenously with one million transformed heart cells, oncogenicity increased with animal passage and a striking increase in the rate of growth of tumours was observed. Furthermore, metastases-a sign of high malignancy - were associated with tumours which have been induced by animal passaged cells. It has been concluded that "oncogenic potential of cells transformed in vitro by SV40 may vary widely and this variation is independent of the presence of the viral genome".

\section{Progress in Thrombosis from a Correspondent}

A CONFERENCE on thrombosis was held in Washington in November to consider the effectiveness of current trends in investigation and how improvements can be made. The conference was sponsored by a task force 